\title{
ARTICLE Role of trace amine-associated receptor 1 in nicotine's behavioral and neurochemical effects
}

\author{
Jian-Feng Liu $\mathbb{D}^{1,2}$, Robert SeamanJr. ${ }^{1}$, Justin N. Siemian ${ }^{1}$, Rohan Bhimani ${ }^{3}$, Bernard Johnson ${ }^{1}$, Yanan Zhang ${ }^{4}$, Qing Zhu ${ }^{1,2}$,
} Marius C. Hoener $\mathbb{i D}^{5}$, Jinwoo Park ${ }^{3}$, David M. Dietz $\mathbb{D}^{1}$ and Jun-Xu Li ${ }^{1}$

Nicotine addiction and abuse remains a global health issue. To date, the fundamental neurobiological mechanism of nicotine addiction remains incompletely understood. Trace amine-associated receptor 1 (TAAR1) is thought to directly modulate dopaminergic system and are thought to be a neural substrate underlying addictive-like behaviors. We aimed to investigate the role of TAAR1 in nicotine addictive-like behaviors. TAAR1 expression after nicotine treatment was evaluated by western blotting. c-Fos immunofluorescence and in vivo fast-scan cyclic voltammetry were used to examine the activation of brain regions and dopamine release, respectively. We then thoroughly and systematically examined the role of TAAR1 in mediating nicotine-induced sensitization, nicotine discrimination, nicotine self-administration, nicotine demand curve, and the reinstatement of nicotineseeking. Local pharmacological manipulation was conducted to determine the role of TAAR1 in the nucleus accumbens (NAcs) in the reinstatement of nicotine-seeking. We found that the expression of TAAR1 protein was selectively downregulated in the NAC, with no change in either dorsal striatum or prefrontal cortex. TAAR1 activation was sufficient to block nicotine-induced c-Fos expression in the NAc, while also reducing nicotine-induced dopamine release in the NAc. Systemic administration of TAAR1 agonists attenuated the expression and development of nicotine-induced sensitization, nicotine self-administration, the reinstatement of nicotine-seeking, and increased the elasticity of nicotine demand curve, while intra-NAc infusions of a TAAR1 agonist was sufficient to attenuate nicotine reinstatement. Moreover, TAAR1-knockout rats showed augmented cue-induced and drug-induced reinstatement of nicotine-seeking. These results indicated that modulation of TAAR1 activity regulates nicotine addictive-like behaviors and TAAR1 represents a novel target towards the treatment of nicotine addiction.

Neuropsychopharmacology (2018) 43:2435-2444; https://doi.org/10.1038/s41386-018-0017-9

\section{INTRODUCTION}

Tobacco use remains a serious global health threat, leading to nearly six million deaths per year [1]. Although there are several Food Drug Administration-approved medications available in helping smoking cessation, the therapeutic efficacy is limited and the relapse rate is high. The primary addictive agent in tobacco is nicotine, which induces psychostimulation and rewarding effects [2]. The psychopharmacological effects of nicotine are due to its binding to the nicotinic acetylcholine receptors within the central nervous system, especially in the mesocorticolimbic system to modulate dopamine (DA) transmission [3]. Therefore, modulators of the mesocorticolimbic DA system could be promising pharmaceutical candidates to treat nicotine addiction.

Nicotine regulates DA transmission through a complex mechanism $[4,5]$. Nicotine enhances the firing rate and the phasic bursts of the dopaminergic neurons in the ventral tegmental area (VTA) and increases DA release in the dopaminergic projecting areas. Nicotine also locally regulates the dopamine transmission in the nucleus accumbens (NAcs) [6, 7]. VTA also receives glutamatergic projections from prefrontal cortex (PFC), which controls the function of DA neurons in the VTA and dopamine release. Neural adaptations after nicotine exposure in these brain regions contributes to nicotine addiction.

Trace amine-associated receptor 1 (TAAR1), a G protein-coupled receptor, has been shown to modulate the activity of the dopamine system [8]. TAAR1 is broadly expressed within the mesocorticolimbic system, including the VTA, NAc, and PFC [9]. Ligands of TAAR1 includes endogenous trace amines and amphetamine-like stimulants [8]. Interestingly, modulation of the TAAR1 system demonstrated a role in the regulation of the effects of drugs of abuse such as amphetamine as well as cocaine, which is not a ligand of TAAR1 [8, 10-13]. However, it is unknown whether TAAR1 could mediate the synaptic plasticity changes and behavioral effects induced by drugs that act on other neurotransmitter systems in the brain such as the acetylcholine system. To the best of our knowledge, no study has investigated the role of TAAR1 in nicotine addiction thus far.

\section{MATERIALS AND METHODS}

All experimental procedures were approved by the Institutional Animal Care and Use Committee, University at Buffalo, the State University of New York, and with the 2011 Guide for the Care and

\footnotetext{
${ }^{1}$ Department of Pharmacology and Toxicology; Program in Neuroscience, University at Buffalo, Buffalo, NY 14214, USA; ${ }^{2}$ School of Pharmacy, Nantong University, 226001

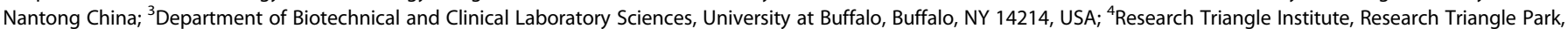
NC 27709, USA and ${ }^{5}$ Neuroscience, Ophthalmology and Rare Disease DTA, pRED, Roche Innovation Center Basel, F Hoffmann-La Roche Ltd, Basel, Switzerland Correspondence: J-X. Li (junxuli@buffalo.edu)
}

Received: 7 August 2017 Revised: 18 January 2018 Accepted: 20 January 2018

Published online: 5 February 2018 
Use of Laboratory Animals (Institute of Laboratory Animal Resources on Life Sciences, National Research Council, National Academy of Sciences, Washington, DC, USA). Please see Methods and materials in Supplement 1 for full experimental details.

\section{Animals}

Adult male Sprague-Dawley rats (initial weight 250-280 g; Harlan, Indianapolis, IN, USA) were housed individually on a 12/12-h light/ dark cycle with free access to water and food except during some experimental sessions. Breeding pairs of TAAR1-knockout (TAAR1KO) rats of Wistar background were gifted by Roche Pharmaceuticals [14]. All TAAR1-KO and wild-type (WT) littermates were obtained from heterozygous mating, and genotyping was performed in all individuals.

\section{Drugs}

Drugs included nicotine tartrate (MP Biomedicals, LLC, Solon, $\mathrm{OH}$, USA), RO5263397 and RO5166017 (synthesized at Research Triangle Institute, purity $>98 \%$ ). Except for the higher dose of RO5263397 (16.7 mg/kg, intraperitoneally (i.p.)) that was used in the nicotine discrimination paradigm, all doses of R05166017 and RO5263397 (3.2, 5.6, and $10 \mathrm{mg} / \mathrm{kg}$, i.p.) were selected based on our previous findings $[11,13,15]$. Nicotine tartrate was dissolved in $0.9 \%$ physiological saline, and the $\mathrm{pH}$ was adjusted to $7.2-7.4$ prior to injection. All of nicotine doses in $\mathrm{mg} / \mathrm{kg}$ in the study represented nicotine base.

Nicotine behavioral sensitization

Nicotine dose-effect curve was determined during each tests on days 1,8 , and 15 [13]. The rats received nicotine treatment on days 2-7 $(1.0 \mathrm{mg} / \mathrm{kg}$, i.p.) followed by 6 days of abstinence in home cages. In the expression experiment, RO5263397 (3.2 and $10 \mathrm{mg} /$ $\mathrm{kg}$, i.p.) was given $20 \mathrm{~min}$ before test on day 15 . In the development experiment, R05263397 (3.2 and $10 \mathrm{mg} / \mathrm{kg}$, i.p.) was given $20 \mathrm{~min}$ before test/nicotine treatment on days $1-7$.

\section{Nicotine discrimination}

Nicotine discrimination was performed in two-lever operant chambers (Coulbourn Instruments Inc., Allentown, PA, USA) as described previously [16]. Rats were trained to discriminate nicotine $(0.4 \mathrm{mg} / \mathrm{kg}$, i.p.) from saline. To verify the validity and pharmacological specificity of our discrimination procedure, we used the noncompetitive antagonist mecamylamine as a positive control, which showed consistent inhibitory effects on the discriminative stimulus effects of nicotine in the previous studies $[17,18]$. Vehicle, RO5263397 (3.2, 10, and $17.8 \mathrm{mg} / \mathrm{kg}$, i.p.), or mecamylamine $(0.1,0.32$, and $1.0 \mathrm{mg} / \mathrm{kg}$, i.p.) were given $10 \mathrm{~min}$ before tests.

\section{Catheterization and stereotaxic surgeries}

Rats were anesthetized with ketamine and xylazine (75 and $5 \mathrm{mg} /$ $\mathrm{kg}$, respectively, i.p.) and implanted with chronic indwelling jugular catheters as previously described $[11,13,19,20]$. In the microinjection experiments, rats also received stereotaxic surgery [21-23]. Coordinate for cannulae: (angle, $10^{\circ}$; anterior-posterior (AP) $+1.7 \mathrm{~mm}$; mediolateral $(\mathrm{ML}) \pm 2.2 \mathrm{~mm}$; dorsoventral (DV) -5.7 $\mathrm{mm}$ ) [24]. Catheters were flushed daily with $0.2 \mathrm{ml}$ solution of enrofloxacin $(4 \mathrm{mg} / \mathrm{ml})$ mixed in a heparinized saline solution (50 $\mathrm{IU} / \mathrm{ml}$ in $0.9 \%$ sterile saline) to preserve catheter patency.

Nicotine self-administration

One week after surgery, rats began nicotine self-administration $(0.03 \mathrm{mg} / \mathrm{kg}$ per infusion, $1 \mathrm{~h} / \mathrm{session}$ per day). The response requirement was gradually increased from FR 1 to FR 3.

Nicotine-intake procedure

Different doses of nicotine $(0.003,0.01$, and $0.1 \mathrm{mg} / \mathrm{kg}$ per infusion) were substituted for the maintenance dose of nicotine.
Vehicle, RO5166017 (5.6 mg/kg and $10 \mathrm{mg} / \mathrm{kg}$, i.p.), or RO5263397 (3.2 and $5.6 \mathrm{mg} / \mathrm{kg}$, i.p.) were administered $10 \mathrm{~min}$ before the sessions.

Nicotine intake demand curve assessment

Behavioral economic demand curve assessment was performed according to our previous description [13]. The nicotine selfadministration behavior was maintained under the progressiveratio (PR) schedule using the series $1,2,4,6,9,12,15,20,25, \ldots$, derived from the formula: response ratio (rounded to nearest integer) $=\left[5 \mathrm{e}^{(\text {injection number } \times 0.2)}\right]-5$ [25]. Vehicle or RO5263397 $(5.6 \mathrm{mg} / \mathrm{kg}$, i.p.) was administered $10 \mathrm{~min}$ before test sessions.

Reinstatement of nicotine-seeking behavior

Following self-administration, rats were given six daily extinction sessions. Cue-induced reinstatement was tested $24 \mathrm{~h}$ after extinction. Rats then underwent re-extinction. Drug $(0.3 \mathrm{mg} / \mathrm{kg}$ nicotine, subcutaneously (s.c.))-induced reinstatement was tested $24 \mathrm{~h}$ after re-extinction [26, 27]. RO5166017 (10 mg/kg, i.p.) or vehicle was administered 10 min before tests.

Intracranial injections followed by behavioral tests RO5166017 (10 $\mu \mathrm{g} / 1 \mu \mathrm{l}$ per side) was microinjected into the NAc immediately before injecting the priming dose of nicotine $(0.32$ $\mathrm{mg} / \mathrm{kg}$, s.c.) followed by reinstatement test. Two days later, rats were microinjected with RO5166017 $10 \mathrm{~min}$ before locomotion test.

Western blotting and immunofluorescent staining

Western blotting and immunofluorescent staining were based on our previous studies with some modifications [21, 28, 29]. Primary antibodies used were as follows: anti-TAAR1 (1:500; Roche) or antiGAPDH (1:2,000; CST, Boston, MA, USA), anti-c-Fos (1:500; Abcam, Cambridge, MA, USA) and either anti-NeuN (1:1,000; Millipore, Billerica, MA, USA), anti-GFAP (1:500; Millipore), or anti-IBA1 (1:500; Wako). The validity and selectivity of TAAR1 antibody was examined by Roche in the previous study [30]. This antibody was also used in another recent study [31]. Western blotting band intensities and GFAP intensity was analyzed by Image J (National Institutes of Health, Bethesda, MD, UA). The number of c-Fospositive, NeuN-positive, and IBA1-positive cells, and activated microglia in these brain regions was counted manually (14). All image acquisition and analyses were conducted by investigators blind to the experimental conditions.

In vivo fast-scan cyclic voltammetry

Rats were anesthetized with urethane $(1.5 \mathrm{~g} / \mathrm{kg})$ and placed in a stereotaxic frame for implantation of a Ag/AgCl reference electrode, a carbon-fiber microelectrode (NAc core: AP $1.2 \mathrm{~mm}$; ML $1.3 \mathrm{~mm}$; DV -7.5 mm), and a stimulating electrode [32, 33]. A bipolar stimulating electrode (Plastics One, Roanoke, VA, USA) positioned above the VTA (AP $-5.2 \mathrm{~mm}$; ML $1.0 \mathrm{~mm}$; DV -8.0 $\mathrm{mm}$ ) [34]. [DA $]_{\max }$ is the maximally evoked catecholamine concentration and $t_{1 / 2}$ is the time for [DA $]_{\max }$ to decay to half of the maximum [34]. For detailed experimental procedures please see Supplemental methods.

Data analysis

All results were presented as mean $\pm \mathrm{SEM}$. In behavioral economic analysis, best-fitting functions using the exponential demand model were fitted to the averaged group data on log-log coordinates $[13,35]$. All other behavioral data and immunofluorescent staining data were analyzed by two-way repeatedmeasures analysis of variance (ANOVA) followed by post hoc Bonferroni's test. Western blotting results were analyzed by twotailed ttest. Fast-scan cyclic voltammetry (FSCV) data were analyzed by one-way ANOVA followed by $t$ test. $P<0.05$ was considered statistically significant. 


\section{RESULTS}

TAAR1 is selectively downregulated in the NAc after nicotine treatment

We first assessed whether TAAR1 was changed by chronic nicotine treatment. We found that the protein level of TAAR1 in the NAC was significantly downregulated by nicotine $\left(t_{13}=2.39, p<0.05\right.$; Fig. 1a). Interestingly, TAAR1 expression was unchanged in the dorsal part of striatum/caudate putamen $\left(t_{13}=0.29, p>0.05\right.$; Fig. $1 b)$ or PFC $\left(t_{11}=0.72, p>0.05\right.$; Fig. $\left.1 c\right)$, demonstrating that nicotine-induced changes in TAAR1 expression are specifically localized to the NAc.

Activation of TAAR1 attenuated nicotine-induced c-Fos expression in the NAC

To assess whether TAAR1 is involved in the neurobiological actions of nicotine, we examined the effects of TAAR1 activation on nicotine-induced protein expression of c-fos, an immediateearly gene marker of neuronal activation. TAAR1 agonist RO5166017 (10 mg/kg, i.p.) was administered before behavioral test. Two-way ANOVA showed significant main effect of nicotine $\left(F_{1,19}=64.66, p<0.001\right), \operatorname{RO} 5166017\left(F_{1,19}=5.30, p<0.05\right)$ and an interaction of nicotine $\times \operatorname{RO} 5166017\left(F_{1,19}=10.72, p<0.01\right)$. Post hocanalysis indicated that TAAR1 activation significantly decreased nicotine-induced hyperactivity $\left(t_{19}=4.04, p<0.01\right)$, but had no effect on saline-treated rats $\left(t_{19}=0.67, p>0.05\right.$; Fig. $1 d$ ). In the c-Fos expression in the NAc, two-way ANOVA analysis showed significant main effects of nicotine $\left(F_{1,19}=5.15, p\right.$ $<0.05), \operatorname{RO} 5166017\left(F_{1,19}=8.39, p<0.01\right)$, and an interaction of nicotine $\times \operatorname{RO} 5166017\left(F_{1,19}=6.60, p<0.05\right)$. Post hoc analysis indicated that nicotine significantly increased c-Fos expression in the NAc $\left(t_{19}=3.34, p<0.01\right)$, which was prevented by TAAR1 activation $\left(t_{19}=3.28, p<0.01\right)$. No difference was found in the $c$ Fos expression in the PFC (main effect of nicotine: $F_{1,19}=0.01, p>$ 0.05; main effect of R05166017: $F_{1,19}=0.71, p>0.05$; Fig. 1e, f). Furthermore, TAAR1 activation had no effect on the expression of the neural marker NeuN, astrocytes marker GFAP, or microglia marker IBA1 (Supplementary Figure S1). These results indicate that TAAR1 in the NAc functionally regulates the biological effects of nicotine.

Activation of TAAR1 reduced nicotine-induced dopamine release in the NAc

Given the hypothesis that TAAR1 modulates the dopaminergic system, we then used in vivo FSCV to study the role of TAAR1 in the effects of nicotine on dopamine release in the NAc evoked by electrical stimulation of the VTA. The color plots showed the evoked signals which are due to dopamine oxidation at $\sim 0.65 \mathrm{~V}$ (dotted white line; Fig. 2a). The dopamine signal increased rapidly during electrical stimulation $(20 \mathrm{~Hz}, 60$ pulses $)$, and nicotine $(0.32$ $\mathrm{mg} / \mathrm{kg}$, i.p.) resulted in a transient increase in evoked dopamine release in the NAC (Fig. 2b; Supplementary Figure S2a). One-way ANOVA was conducted to analyze the nicotine-induced maximal dopamine release $\left(\mathrm{DA}_{[\mathrm{max}]}\right)$ after vehicle or TAAR1 agonist RO5166017 (10 mg/kg, i.p.), indicating a significant effect $\left(F_{3,17}\right.$ $=52.28, p<0.001)$. Follow-up $t$ test showed that nicotine significantly increased electrically evoked dopamine release compared to vehicle $\left(t_{6}=5.74, p<0.001\right)$, which was decreased by TAAR1 activation $\left(t_{7}=7.93, p<0.001\right)$. Interestingly, RO5166017 alone significantly reduced dopamine release $\left(t_{7}=\right.$ $6.32, p<0.001$; Fig. 2c), but had no effect on the half-life $\left(t_{1 / 2}\right)$ of dopamine (Supplementary Figure S2b). These data suggest that TAAR1 activation mediates nicotine-induced dopamine release in the NAc.

TAAR1 activation attenuated the expression and development of nicotine-induced behavioral sensitization

We then examined the effects of TAAR1 activation on a series of abuse-related behaviors of nicotine. We first tested the effects of the TAAR1 partial agonist R05263397 on nicotine-induced sensitization. After repeated treatment, rats were sensitized to nicotine $\left(F_{2,96}=23.56, p<0.001\right.$; vehicle group in Fig. $\left.3 a\right)$. In the expression of nicotine-induced sensitization experiment, all groups of rats showed similar nicotine dose-effect curves during tests on day $1\left(F_{2,26}=1.87, p>0.05\right)$ and day $8\left(F_{2,26}=0.02, p>\right.$ 0.05). In the expression test (day 15), RO5263397 dosedependently reduced the dose-effect curve of nicotine $\left(F_{2,26}=\right.$ $7.67, p<0.01)$. Post hoc analysis indicated that $10 \mathrm{mg} / \mathrm{kg}$ R05263397 decreased the response to nicotine at doses of $0.32-1.0 \mathrm{mg} / \mathrm{kg}$ (all $p<0.05$; Fig. 3a).

In the development of nicotine-induced sensitization experiment, RO5263397 was administered from day 1 to day 7 (Fig. 3b). We found that RO5263397 attenuated the effect of acute nicotineinduced hyperactivity on day $1\left(F_{2,24}=4.96, p<0.05\right)$. The nicotine dose-effect curve on day 8 was reduced $\left(F_{2,24}=5.14, p=0.01\right.$; Fig. $3 \mathrm{~b}$ middle panel). After abstinence (day 15), rats that were treated with $10 \mathrm{mg} / \mathrm{kg}$ RO5263397 remained demonstrating a lower level of nicotine-induced hyperactivity $\left(F_{2,24}=2.92, p=\right.$ $0.07 ; t_{17}=3.11, p<0.01$; Fig. $\left.3 b\right)$. Our previous result showed that RO5263397 (1-10 mg/kg) alone had no effect on locomotion [36]. These data indicated that TAAR1 activation decreased the expression and development of nicotine-induced behavioral sensitization.

TAAR1 activation attenuated the discriminative stimulus effects of nicotine

The subjective effects of psychostimulants such as nicotine are one of the important facets that contribute to drug addiction [37]. To this end, we examined whether TAAR 1 agonist could attenuate the discriminative stimulus effects of nicotine. Rats were trained to discriminate between nicotine from saline (Fig. 3c, d). Two-way ANOVA analysis showed significant main effects of nicotine $\left(F_{3,84}\right.$ $=43.38, p<0.001)$, TAAR1 agonist R05263397 $\left(F_{3,28}=7.69, p<\right.$ $0.001)$, and nicotine $\times$ RO5263397 interaction $\left(F_{9,84}=2.296, p<\right.$ $0.05)$. RO5263397 also dose-dependently affected the response rate $\left(F_{3,28}=18.39, p<0.001\right)$. Post hoc analysis indicated that RO5263397 at the dose of $10 \mathrm{mg} / \mathrm{kg}$ significantly reduced the discriminative stimulus effect of nicotine $\left(t_{28}=3.47, p<0.01\right.$; Fig. $3 c$, left) without affecting the response rate $\left(t_{28}=2.45, p>\right.$ 0.05 ; Fig. 3d, left). As expected, the nicotinic receptor antagonist mecamylamine also attenuated the discriminative effects of nicotine $\left(F_{3,28}=13.44, p<0.001\right.$; Fig. $3 c$, left $)$ without affecting the response rate $\left(F_{3,28}=0.26, p=0.85\right.$; Fig. $3 d$, right). These results indicated that TAAR1 activation attenuated the subjective effects of nicotine.

TAAR1 activation reduced nicotine self-administration Next, we tested the role of TAAR1 on nicotine self-administration. Inverted U-shaped dose-effect curves of nicotine were established (Fig. 3e; Supplementary Figure S3a)). Two-way repeated-measures ANOVA was conducted to analyze the effects of TAAR1 agonists on nicotine self-administration, indicating significant main effects of the TAAR1 agonist $\operatorname{R05166107}\left(F_{2,56}=24.13, p<0.001\right.$; Fig. 3e, left) and the TAAR1 agonist R05263397 $\left(F_{2,54}=41.25, p<0.001\right.$; Fig. 3e, right). Post hoc analysis showed that both TAAR1 agonists dose-dependently decreased the number of nicotine infusions ( $p$ $<0.05$ ) and total nicotine consumption (Supplementary Figure S3c, d). These results indicated that TAAR1 activation attenuated nicotine self-administration.

TAAR1 activation increased the elasticity of nicotine demand curve We then used an economic demand curve analysis to evaluate the role of TAAR1 in the ability of nicotine to maintain responding at progressively higher prices. Rats underwent nicotine selfadministration under a PR (Supplementary Figure S3b). TAAR1 agonist RO5263397 significantly shifted the nicotine demand curve downward ( $p<0.001$; Fig. $3 f$, left). The estimated nicotine 
A.
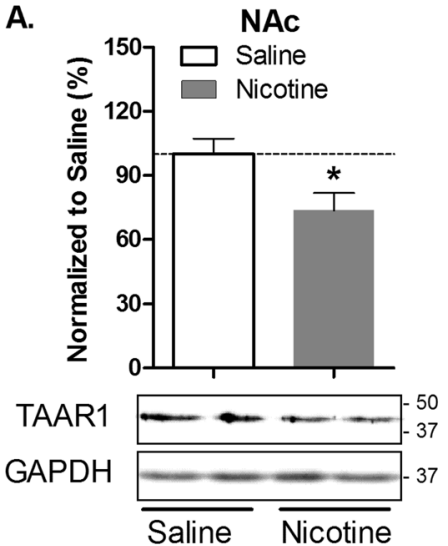

D.
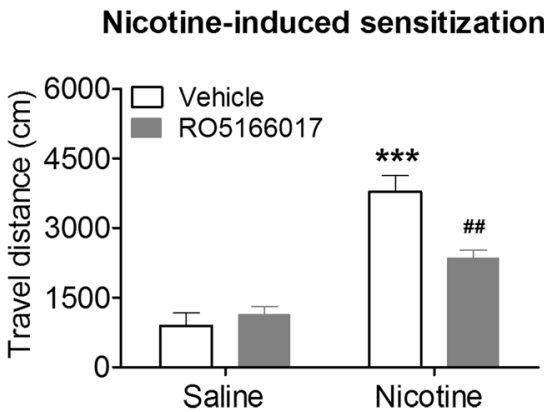

F.
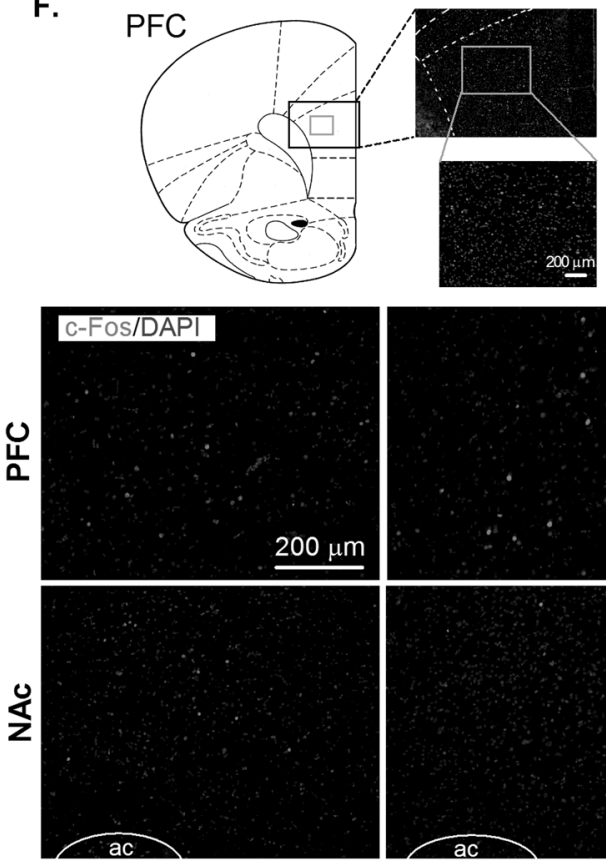

Saline-Vehicle
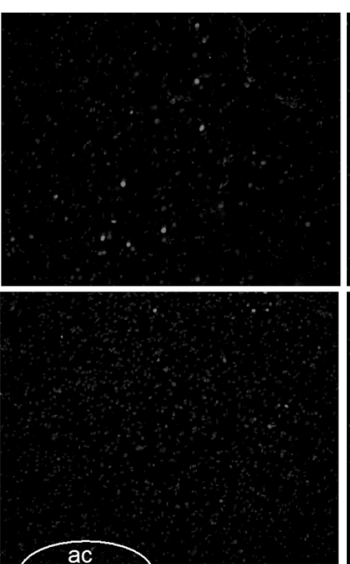

Saline-RO
B. $\mathrm{CPU}$
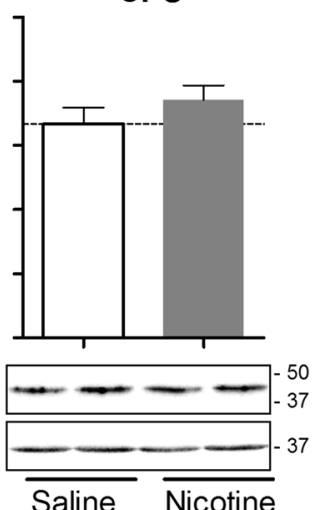

C.

PFC
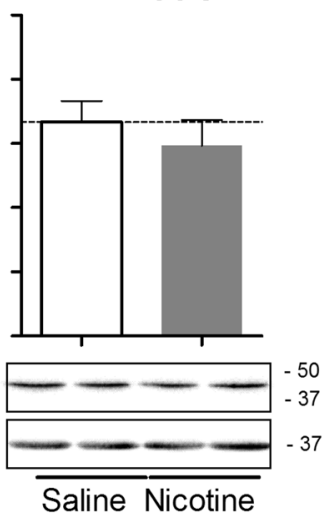

\section{$-50$}

37

Saline Nicotine
E.
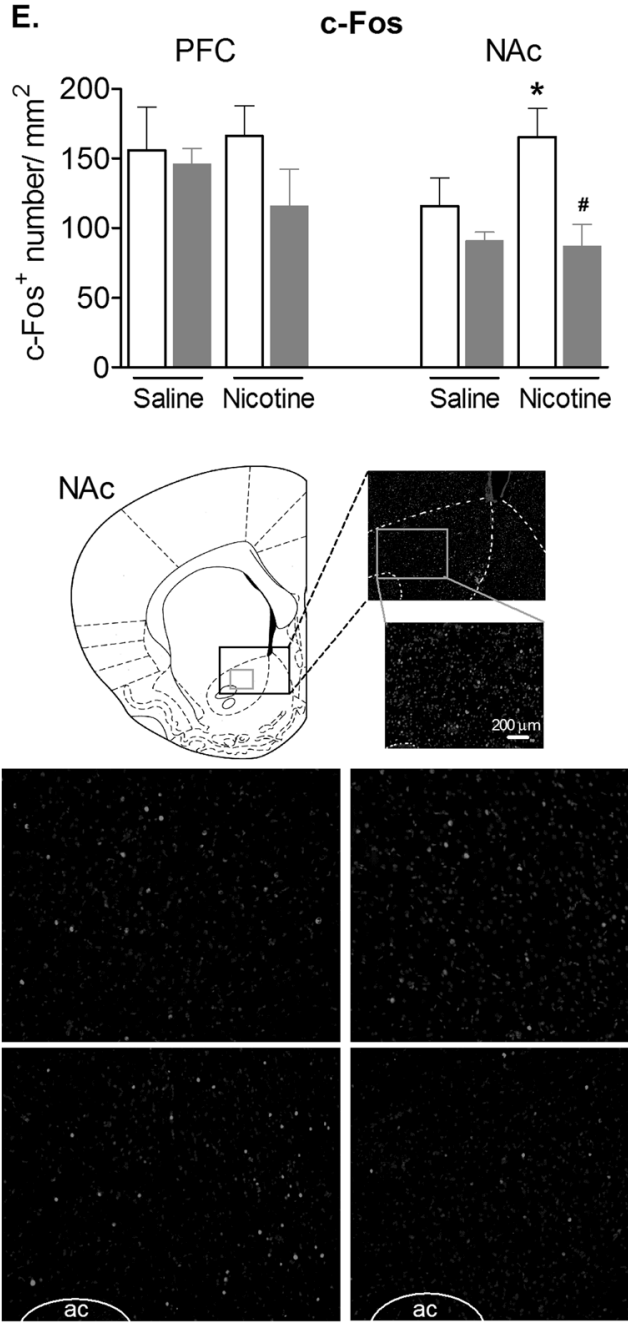

Nicotine-Vehicle
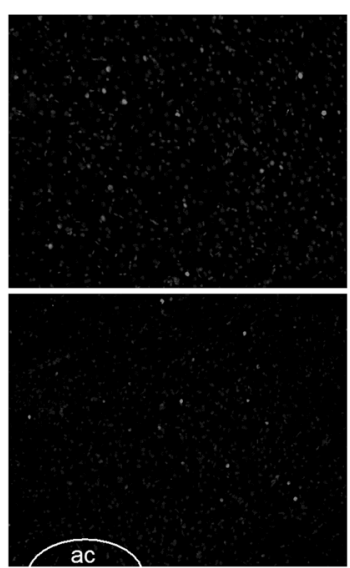

Nicotine-RO

Fig. 1 Effects of nicotine treatment on TAAR1 expression, and effects of TAAR1 activation on nicotine-induced c-Fos expression. a-c Nicotine exposure significantly reduced the level of TAAR1 protein in the NAc ( $n=7-8$ per group), but not in the CPU ( $n=7-8$ per group) or the PFC ( $n$ =6-7 per group). d TAAR1 agonist RO5166017 attenuated nicotine-induced behavioral sensitization. e TAAR1 agonist RO5166017 reduced nicotine-induced increase in the number of c-Fos-positive cells in the NAc. No difference among all groups was found in the PFC. $\mathbf{f}$ Representative images of c-Fos staining. AC anterior commissure. Data are expressed as mean \pm SEM; ${ }^{*} p<0.05$, ${ }^{* * *} p<0.001$, compared with saline or saline-vehicle group; ${ }^{\#} p<0.05$, \#\# $p<0.01$, compared with nicotine-vehicle group. Saline-vehicle, $n=5$; other groups, $n=6$ per group

consumption when the price was $0\left(Q_{0}\right)$ was significantly reduced by RO5263397 (injections: $15.87 \pm 2.74$ vs. $5.11 \pm 1.34 ; p<0.05$ ). R05263397 increased the $a$-value of the nicotine demand curve $(0.003589 \pm 0.0006029$ vs. $0.001113 \pm 0.0001264 ; p<0.05)$.
Furthermore, curve-fitting analysis of the data from individual subjects revealed that the $Q_{0}$ was significantly reduced by R05263397 ( $t_{15}=2.62, p<0.05$; Fig. 3f, middle). A significant increase in the essential value $(a)$ of nicotine $\left(t_{15}=2.70, p<0.05\right.$; 
A.
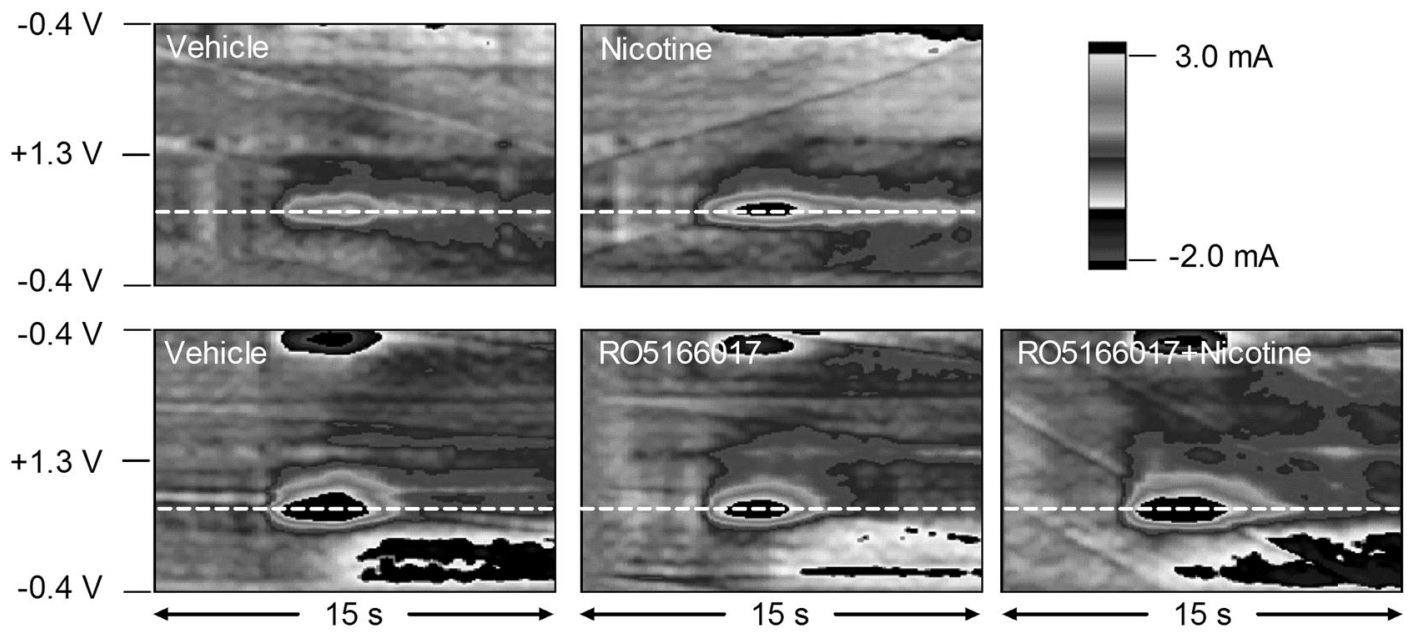

B.

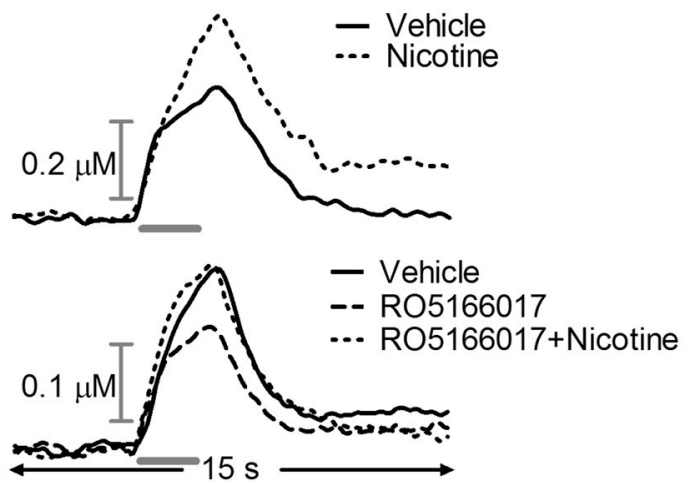

C.

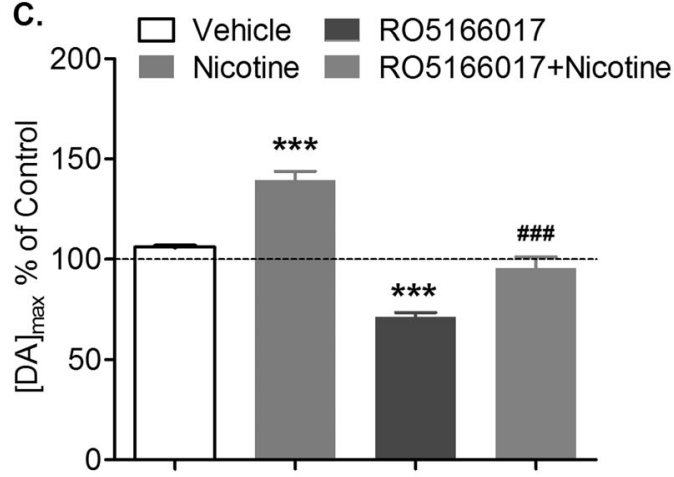

Fig. 2 TAAR1 activation reduced nicotine-induced dopamine release in the NAc. a Representative color plots of electrically evoked dopamine. Data are presented as $5 \mathrm{~s}$ before and $10 \mathrm{~s}$ after electrical stimulation. Dopamine concentration changes are apparent in the color plots for their oxidation $(\sim 0.65 \mathrm{~V}$, indicated by dotted white line) and reduction $(\sim-0.29 \mathrm{~V}$, indicated by solid white line) potentials. b Representative concentration vs. time traces of dopamine release evoked by electrical stimulation of the VTA $(20 \mathrm{~Hz}, 60 \mathrm{pulses}, 300 \mu \mathrm{A})$. c TAAR1 agonist RO5166017 reduced dopamine release and prevented nicotine-induced dopamine release in the NAc. [DA] max maximal dopamine level. Data are expressed as mean \pm SEM; ${ }^{* * *} p<0.001$, compared with saline-vehicle group; ${ }^{\# \#} p<0.01$, compared with nicotine group. Vehicle and nicotine groups, $n=4 ; \mathrm{RO}$ and $\mathrm{RO}+$ nicotine groups, $n=5$

Fig. 3f, right) was also revealed, suggesting that the nicotine demand curve was more elastic in the presence of RO5263397. A more elastic demand curve indicates that the commodity is less essential and the consumption decreases more quickly with price increase. These data indicated that TAAR1 activation increased the elasticity of nicotine demand curve.

TAAR1 activation suppressed the reinstatement of nicotineseeking behavior

We then tested whether TAAR1 was involved in the reinstatement of nicotine-seeking behavior, a model of drug relapse [26, 27]. Rats underwent nicotine self-administration and extinction (Fig. 4a, b). No difference was found between the two groups of rats that selfadministered nicotine during training or extinction (Supplementary Figure S4a, b). Two-way repeated-measures ANOVA analyzed the cue-induced reinstatement data, indicating significant main effects of Test $\left(F_{1,22}=22.73, p<0.001\right)$ and Group $\left(F_{2,22}=6.034, p\right.$ $<0.01)$, and an interaction of Test $\times$ Group $\left(F_{2,22}=6.146\right.$, $p<0.01)$. Post hoc analysis showed that TAAR1 agonist R05166017 significantly reduced the cue-induced reinstatement of nicotine-seeking $\left(t_{16}=3.87, p<0.001\right.$; Fig. $\left.4 c\right)$. Rats were then re-extinguished and underwent drug-induced reinstatement test. Two-way repeated-measures ANOVA showed significant main effects of Test $\left(F_{1,22}=16.56, p<0.001\right)$ and Group $\left(F_{2,22}=11.13, p\right.$ $<0.001)$, and an interaction of Test $\times \operatorname{Group}\left(F_{2,22}=7.302, p<\right.$
0.01). RO5166017 significantly attenuated drug-induced reinstatement of nicotine-seeking $\left(t_{16}=5.41, p<0.001\right.$; Fig. 4d). TAAR1 activation did not affect the inactive lever presses (Supplementary Figure S4c-f). These results indicated that TAAR1 activation reduced cue-induced and drug-induced reinstatement of nicotine-seeking behaviors.

We then tested the effect of TAAR1 activation on nicotineinduced hypothermia, a non-abuse-related behavioral effect of nicotine. TAAR1 agonist RO5263397 at a dose of $3.2 \mathrm{mg} / \mathrm{kg}$ had no effect on nicotine-induced hypothermia. A higher dose of RO5263397 $(10 \mathrm{mg} / \mathrm{kg})$ alone significantly reduced the body temperature and also shifted the nicotine-induced hypothermia dose-effect curve downward, possibly due to a simple additive effect (Supplementary Figure S5). Taken together, these results indicated that TAAR1 agonists specifically attenuate abuse-related effects of nicotine.

Knockout of TAAR1 augmented the reinstatement of nicotineseeking

To test whether endogenous TAAR1 is involved in nicotine-related behaviors, we compared the reinstatement of nicotine-seeking behaviors between TAAR1-KO rats and their WT littermates. Twoway ANOVA analysis did not found difference between two genotypes of rats during self-administration (main effect of genotype: $\left.F_{1,44}=0.08, p>0.05\right)$ or extinction $\left(F_{1,44}=0.02, p>\right.$ 
A.

Expression of sensitization

Day 1

Day 8

Day 15

.. $_{\text {EO }}^{\text {RO5263397 (mg/kg): }}$

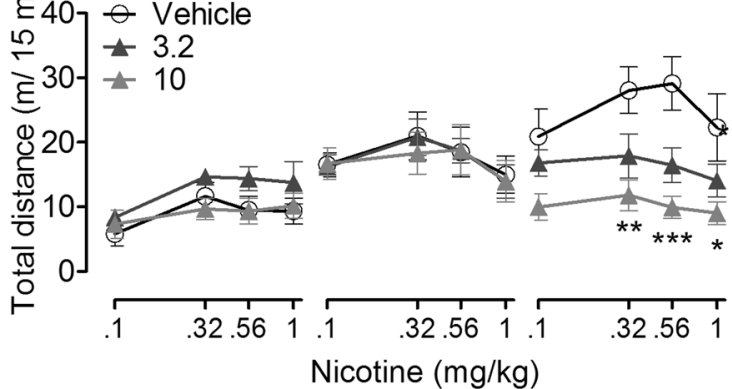

C.

\section{Nicotine discrimination}

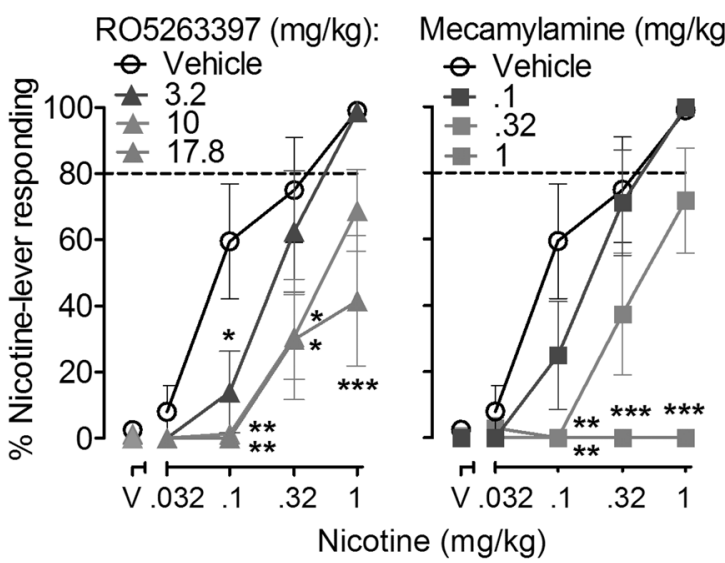

E.

\section{Nicotine intake}

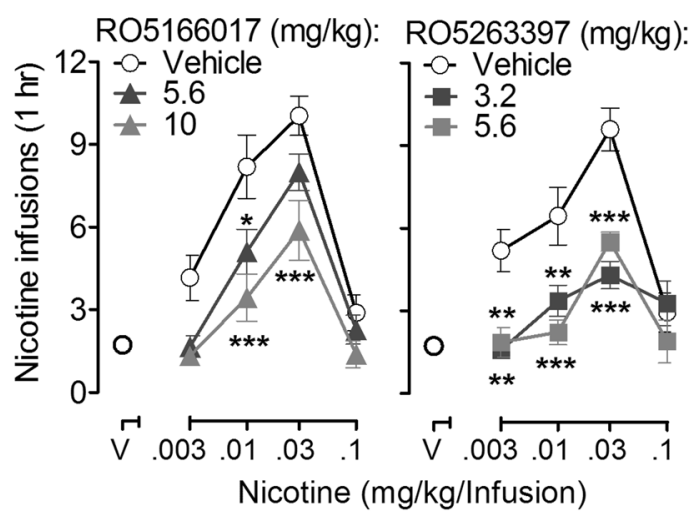

\section{B. Development of sensitization}
Day 1
Day 8
Day 15

$\mathrm{RO5263397} \mathrm{(mg/kg):}$

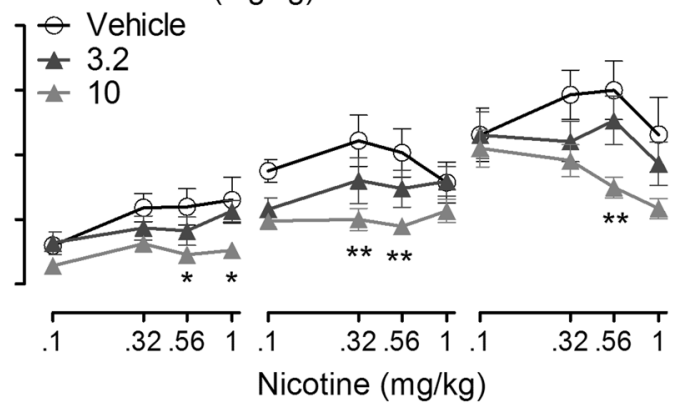

D.

Response rate

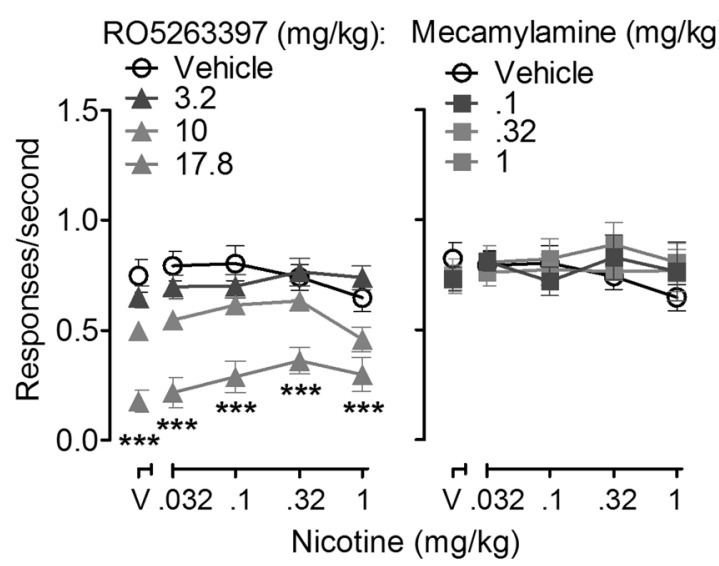

F.

Nicotine demand curve
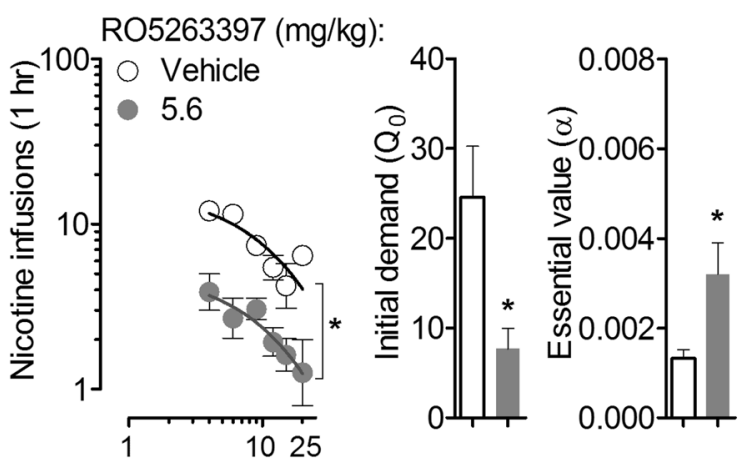

Fig. 3 Effects of TAAR1 activation on nicotine-induced behavioral sensitization, nicotine discrimination, nicotine self-administration, and nicotine demand curve. a TAAR1 agonist RO5263397 reduced the expression of nicotine-induced sensitization (vehicle, $n=9 ; 3.2$ and 10 RO, $n$ $=10$ per group). b TAAR1 agonist RO5263397 attenuated acute nicotine-induced hyperactivity and the development of nicotine-induced sensitization (vehicle, $n=8 ; 3.2 \mathrm{RO}, n=9 ; 10 \mathrm{RO}, n=10$ ). c TAAR1 agonist RO5263397 and nicotinic receptor antagonist mecamylamine dosedependently attenuated the average percentage of responding on the nicotine-appropriate lever ( $n=8$ per group). d TAAR1 agonist RO5263397 only at the dose of $17.8 \mathrm{mg} / \mathrm{kg}$ decreased rates of responding. Mecamylamine had no effect on rates of responding. e TAAR1 agonist RO5166017 and R05263397 dose-dependently reduced nicotine self-administration (saline rats, $n=6 ;$ nicotine rats, $n=9$ ). $\mathbf{f}$ TAAR1 agonist RO5263397 shifted the nicotine demand curve downward, reduced estimate of consumption at zero price $\left(Q_{0}\right)$, and increased the essential value $(a)$ of nicotine $(n=9)$. Symbols above "V" represent vehicle. Data are expressed as mean $\pm \mathrm{SEM} ;{ }^{*} p<0.05,{ }^{* *} p<0.01,{ }^{* * *} p<$ 0.001 , compared with vehicle

0.05; Fig. 4e). For the cue-induced reinstatement test, two-way ANOVA showed significant main effects of lever $\left(F_{1,11}=59.46\right.$, $p<0.001)$ and genotype $\left(F_{1,11}=8.41, p<0.05\right.$; Fig. $\left.4 f\right)$. For the drug-induced reinstatement test, two-way ANOVA also showed significant main effects of lever $\left(F_{1,11}=79.78, p<0.001\right)$ and genotype $\left(F_{1,11}=5.59, p<0.05\right)$, and an interaction of lever $\times$ genotype $\left(F_{1,11}=5.85, p<0.05\right.$; Fig. $\left.4 \mathrm{~g}\right)$. Post hoc analysis indicated that the TAAR1-KO rats showed significant higher responses during the reinstatement of nicotine-seeking (Cueinduced: $t_{20}=3.03, p<0.05$; Drug-induced: $t_{20}=3.33, p<0.01$ ) 


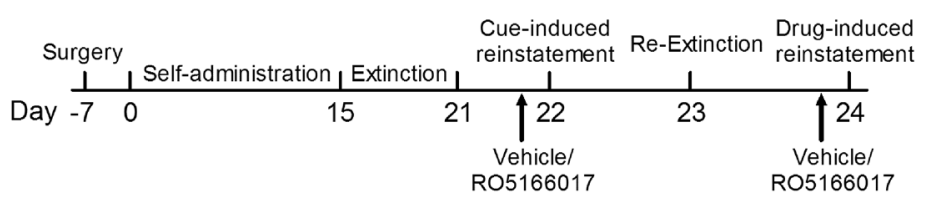

B. Nicotine Self-administration Extinction
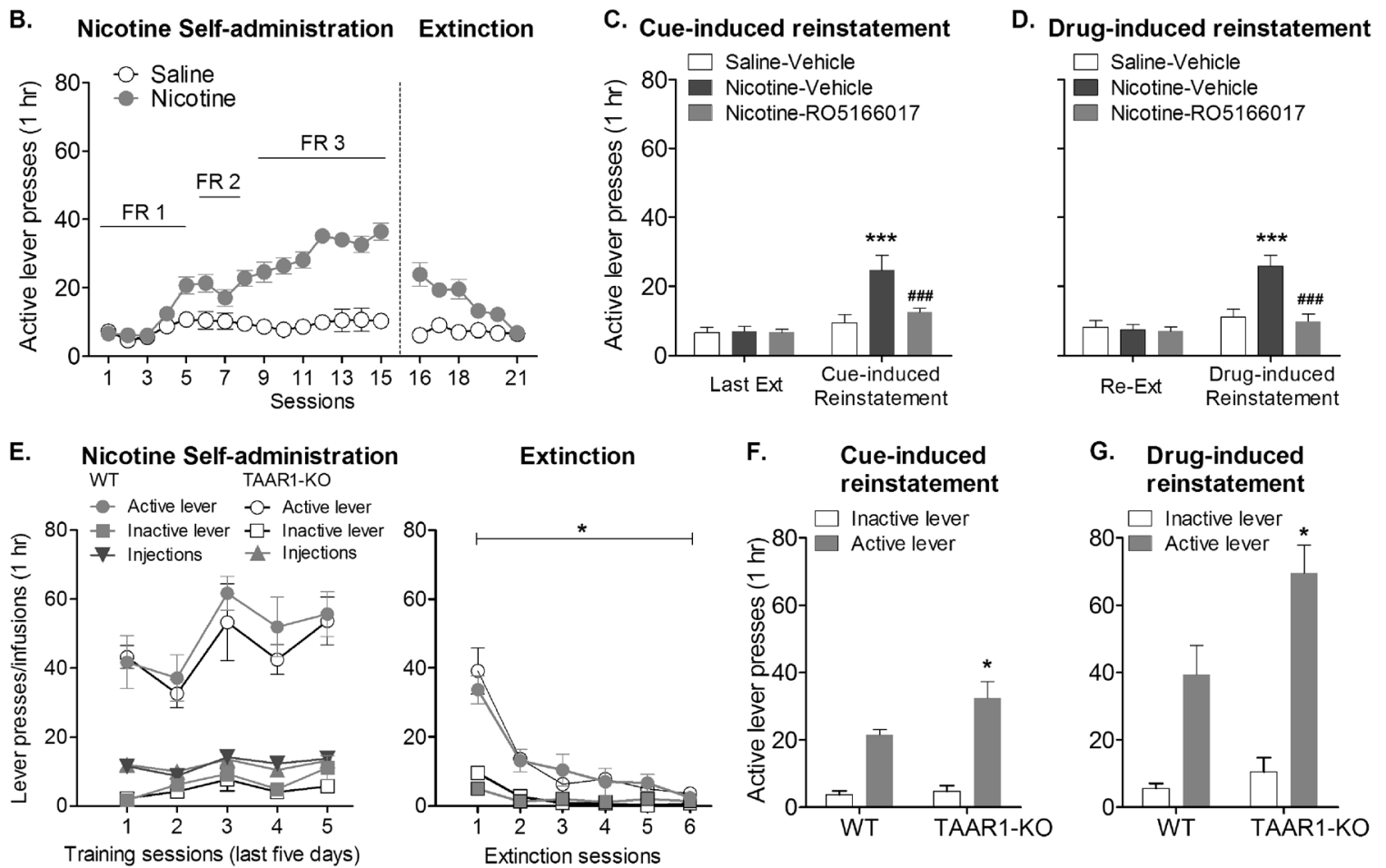

Fig. 4 Role of TAAR1 in cue-induced and drug-induced reinstatement of nicotine-seeking. a Timeline for this experiment. b Rats that selfadministered nicotine ( $n=9$ per group) consistently responded more in the active lever compared to rats in the saline group ( $n=7$ ). Successful extinction was achieved after six sessions of extinction. c TAAR1 agonist RO5166017 attenuated cue-induced reinstatement of nicotine-seeking. d TAAR1 agonist R05166017 decreased priming-induced reinstatement of nicotine-seeking. e No difference was found during nicotine self-administration or extinction between WT and TAAR1-KO rats $(n=6-7$ per group). f TAAR1-KO rats showed higher responses during cue-induced reinstatement of nicotine-seeking. $g$ TAAR1-KO rats showed higher responses during nicotine priming-induced reinstatement of nicotine-seeking. Data are expressed as mean $\pm \mathrm{SEM} ;{ }^{*} p<0.05,{ }^{* * *} p<0.001$, compared with saline-vehicle group or WT group; ${ }^{\# \#} p<0.001$, compared with nicotine-saline group. WT wild type, KO knockout.

compared to WT littermates (Fig. 4f,g). These results indicated that knockout of TAAR1 enhanced the reinstatement of nicotineseeking behavior.

Activation of TAAR1 in the NAc reduced the reinstatement of nicotine-seeking

We then examined the role of TAAR1 in the NAc in the reinstatement of nicotine-seeking. Rats underwent nicotine selfadministration and extinction. No difference was found between two groups of rats during self-administration $\left(F_{1,20}=0.63, p>0.05\right.$; Fig. 5a). During extinction, two-way ANOVA showed a significant main effect of extinction $\left(F_{5,100}=32.86, p<0.001\right)$ but no difference between two groups $\left(F_{1,20}=1.07, p>0.05\right.$; Fig. $\left.5 b\right)$. The TAAR1 agonist RO5166017 was microinjected into the NAc before the reinstatement test (Fig. 5e). Two-way ANOVA showed significant main effects of lever $\left(F_{1,20}=70.04, p<0.001\right)$ and RO5166017 $\left(F_{1,20}=6.44, p<0.05\right)$, and an interaction of lever $\times$ RO5166017 $\left(F_{1,20}=5.88, p<0.05\right)$. Post hoc analysis indicated that TAAR1 activation in the NAC significantly reduced the reinstatement of nicotine-seeking $\left(t_{20}=2.49, p<0.05\right.$; Fig. $\left.5 c\right)$. Moreover, R05166017 had no effect on the locomotor activity $\left(F_{1,20}=0.01\right.$, $p>0.05$; Fig. $5 d$ ). Taken together, these results indicated that the TAAR1 in the NAc played a critical role in the reinstatement of nicotine-seeking.

\section{DISCUSSION}

Taken together, our data here presents a compelling case for TARR1 as an essential regulator of the neurobiological and behavioral consequence of nicotine exposure and addictive-like behaviors. Our findings demonstrate that nicotine exposure regulates TAAR1 expression and through the use of selective pharmacological tools, TAAR1 governs nicotine-induced behavioral plasticity.

TAAR1 regulates nicotine behavioral effects by modulating dopamine release in the NAcs

TAAR1 is expressed widely in the brain, especially in the monoamine systems [9]. Our present study showed that TAAR1 was selectively downregulated in the NAc but not dorsal striatum or the PFC after exposure to nicotine. Importantly, TAAR1 activation attenuated nicotine-induced c-Fos expression in the NAc. Astrocytes could contribute to drug addiction by modulating glutamate homeostasis in the synapse cleft to protect neurons from excitotoxicity [38]. However, our present results showed that TAAR1 activation had no effect on the expression of GFAP in the NAC or PFC. These results indicated that TAAR1 in the NAC, which acts primarily on neurons, is critical for nicotine behavioral effects.

Most studies that suggested the role of TAAR1 in DA transmission were from ex vivo FSCV experiments. It has been 
A.

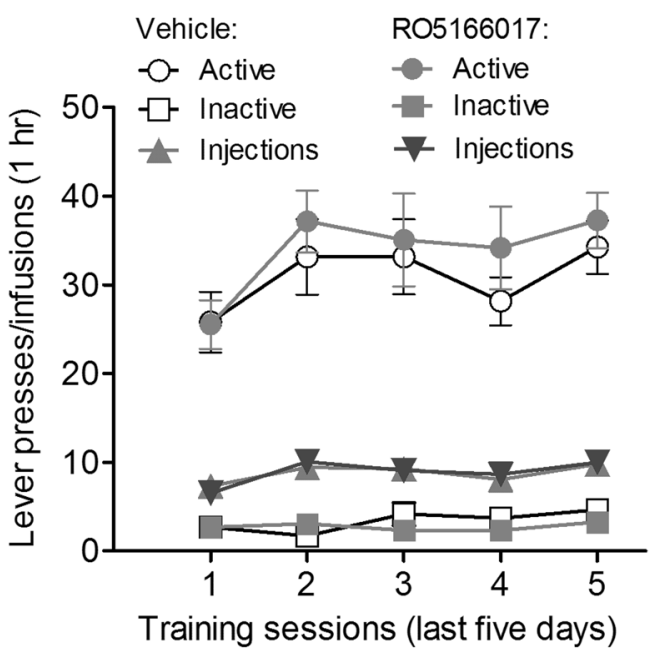

B. Extinction

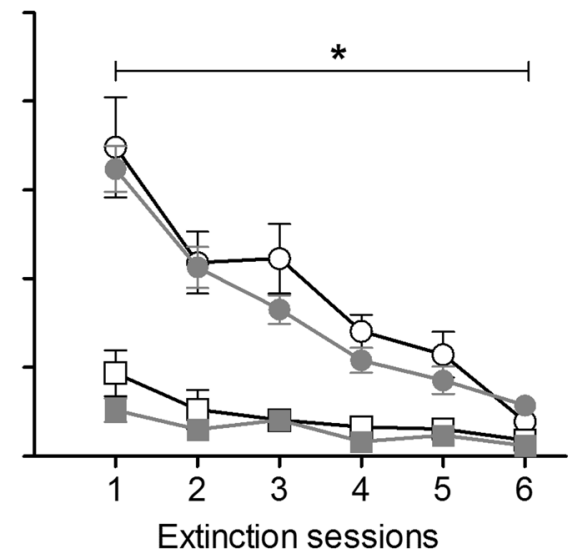

C.

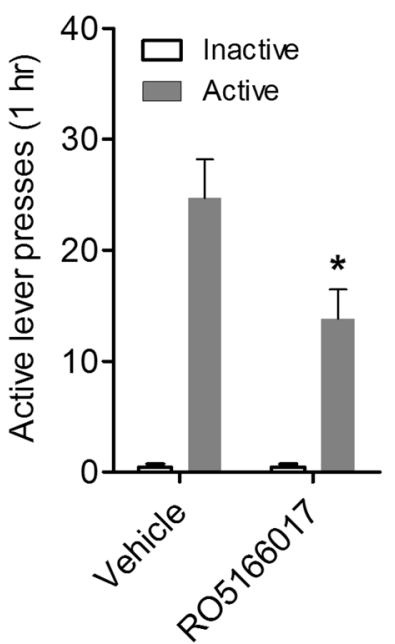

D.

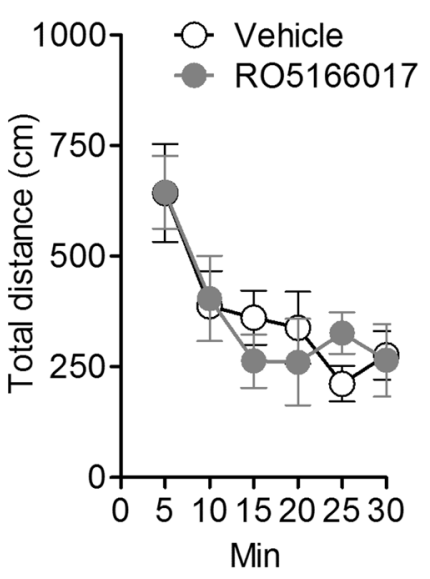

E. Nucleus accumbens

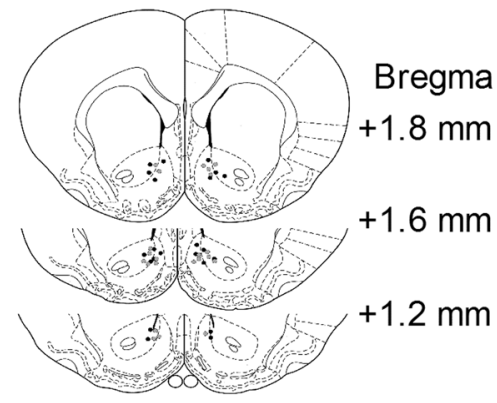

Fig. 5 Local pharmacological activation of TAAR1 in the NAc decreased the reinstatement of nicotine-seeking. a Lever presses on the last 5 days of training. b Successful extinction was achieved after six sessions of extinction. c Microinjection of RO5166017 into the NAc significantly reduced the reinstatement of nicotine-seeking ( $n=11$ per group). d Microinjection of RO5166017 into the NAc did not affect locomotor activity. e Atlas of injection site. Gray dots are for vehicle group and dark dots are for RO5166017 group. Data are expressed as mean $\pm \mathrm{SEM} ;{ }^{*} p<0.05$, compared with vehicle group

shown that DA level was increased in the NAc but not the dorsal striatum in TAAR1 ${ }^{-1-}$ mice [39]. TAAR1 agonists blocked methamphetamine-induced and cocaine-induced DA overflow in the NAC [10, 12, 40]. Although those experiments provided important understanding of the role of TAAR1 in modulating DA transmission, they do not necessarily reflect true in vivo situations where the microenvironment is much more complex-nor do any of the previous studies examine TAAR1's role in the modulation of dopamine following nicotine administration. In the present study, using the in vivo FSCV technique allowed us to demonstrate that the TAAR1 full agonist RO5166017, at the same dose that showed inhibitory effects on nicotine-related behaviors, prevented nicotine-induced DA overflow in the NAc. Our results showed that RO5166017 alone decreased the evoked dopamine release, suggesting the prevention on nicotine-induced DA transmission was a functional (compensatory) attenuation. TAAR1 activation had no effect on the half-life of DA in the NAC, which is consistent with previous in vitro report and suggests that the TAAR1 agonists' actions are at least partially independent of the DAT [39].
One caveat of these results is that we only used a low-frequency stimulation that yielded a steady-state current rather than a peakshaped current in the absence of the drug. It should be noted that the vehicle of RO5166017 contained 5\% ethanol and it is possible (although unlikely) that the observed dopamine release under the vehicle and nicotine conditions could also involve some effect attributable to ethanol. The dose of ethanol the rats received in the study was $<40 \mathrm{mg} / \mathrm{kg}$, far lower than the typical behaviorally or neurochemically active doses [41]. Taken together, these results suggested that TAAR1 could functionally reduce dopamine transmission, which may be, in part, the mechanism by which TAAR1 attenuates nicotine-related behaviors.

TAAR1 activation attenuates abuse-related behaviors of nicotine We systematically demonstrated the inhibitory effects of TAAR1 activation on a broad range of nicotine-related behaviors. We showed that activation of TAAR1 reduced the development and expression of nicotine-induced sensitization, suggesting that TAAR1 could interfere with repeated nicotine exposure-induced 
behavioral neuroplasticity, which are consistent with our previous reports on cocaine $[13,36]$. In the nicotine behavioral sensitization experiment, a cumulative dosing procedure was used to determine the dose-effect curves of nicotine, and the effects could be different from single dose studies due to the differing pharmacokinetics. We also showed that TAAR1 activation attenuated the discriminative stimulus effects of nicotine in a manner that was similar to the nicotinic receptor antagonist mecamylamine. Drug-induced discriminative stimulus effects are highly related to the subjective effects in humans and correlated to its reinforcing effects and abuse potential $[42,43]$. These findings suggest that TAAR1 activation could reduce nicotine-induced subjective effects, which may contribute to reduced nicotine selfadministration (see below).

TAAR1 activation also reduced nicotine self-administration, the reinforcing strength of nicotine, and the reinstatement of nicotineseeking behavior. First, both a TAAR1 full agonist RO5166017 and a partial agonist R05263397 dose-dependently shifted the nicotine self-administration dose-response curve downward. According to previous ex vivo electrophysiological studies, the TAAR1 partial agonist R05263397 and full agonist RO5166017 act oppositely on the dopaminergic neuron in the VTA, with RO5166017 inhibiting while R05263397 potentiating the firing rate of VTA neurons, respectively [44, 45]. However, previous results suggest that TAAR1 full agonists and partial agonists showed similar pharmacological effects in their abilities to affect several different behaviors $[15,45]$. Such a discrepancy is currently difficult to reconcile because of the lack of sufficient evidence but we believe the most likely interpretation is due to the difference between the simplified ex vivo VTA-containing brain slice microenvironment and the complexity of behavioral determination. Nevertheless, there is no doubt that both are mediated by TAAR1 as the effects of the TAAR1 agonists disappeared in TAAR1KO animals. Second, TAAR1 agonist RO5263397 decreased the consumption and reinforcing strength of nicotine in the economic demand curve analysis. In our previous study, we showed that RO5263397 decreased the essential value of cocaine, but did not affect the initial consumption of cocaine [13]. The different effects in cocaine and nicotine by RO5263397 may be caused by the different reinforcing strength of cocaine and nicotine [46]. Finally, the TAAR1 agonist RO5166017 significantly reduced cue-induced and priming-induced reinstatement of nicotine-seeking behaviors in the reinstatement model, which suggested that TAAR1 agonists could be effective in treating relapse to nicotine use. The essential role of TAAR1 in modulating nicotine behavioral effects was further supported by the finding that TAAR1-KO rats demonstrated enhanced reinstatement to both the environmental cueinduced and drug-induced reinstatement of nicotine-seeking behavior. We previously reported that the TAAR1 agonist RO5263397 alone did not induce conditioned place aversion [13]. Taken together, our present results demonstrated selective inhibitory effects of TAAR1 activation on the abuse-related effects of nicotine.

Cellular Mechanisms of TAAR1 in nicotine behavioral effects The rewarding and reinforcing effects of nicotine are partially mediated by activating dopaminergic neurons and by locally acting in the areas wherein dopaminergic neurons project [6]. The effects of the systemic activation of TAAR1 on nicotine-induced abuse-related effects may also act in both ways. First, TAAR1 in the VTA may directly inhibit the firing rate of dopaminergic neurons [10]. Second, TAAR1 in the NAC may affect dopamine release or reuptake locally [39]. Considering the distinct effects of TAAR1 full and partial agonists on the firing rate of dopaminergic neuron in the VTA but similar effects of these two kinds of agonists on nicotine-related behaviors, we believe that TAAR1 activation in the $\mathrm{NAc}$ is the common mechanism that underlies the effects of systemic administration of TAAR1 agonists $[47,48]$. This also better fits with the current proposed theory that TAAR1 mainly regulates presynaptic activity to modulate dopamine concentration $[8,49]$. Furthermore, we found that local pharmacological activation of TAAR1 in the NAc attenuated the reinforcing effects of nicotine. In addition, our previous study have shown that TAAR1 activation in the NAc did not affect food reinforced operant responding [11]. However, the precise cellular mechanism underlying the role of TAAR1 in drug addiction is still elusive. The existing view of TAAR1 in dopamine transmission focuses on the interaction of TAAR1 with D2 autoreceptors and/or DAT [8, 10, 39, 44, 50]. Recently, it has been demonstrated that postsynaptic D2 receptors are also involved in the role of TAAR1 [14]. Moreover, TAAR1 activation could interact with Kir3 channels to regulate $G$ protein-dependent inwardly rectifying $\mathrm{K}^{+}$current [51]. Additionally, TAAR1 was suggested to mainly express intracellularly, while the membrane expression of TAAR1 would be enhanced when co-expressed with D2R, which makes the cellular mechanisms more complicated. Further studies are required to clarify the cellular mechanisms underlying the function of TAAR1.

In summary, these findings demonstrated that TAAR1 regulates nicotine use and indicate that TAAR1 agonists could be novel pharmacological interventions rather than a replacement therapy in the treatment of nicotine use.

\section{ACKNOWLEDGEMENTS}

We would like to thank Dr. Fraser Sim and Dr. Zi-Jun Wang for their technical expertise in microscopy and immunostaining.

\section{FUNDING}

This work was supported by the National Institutes of Health National Institute on Drug Abuse (Grant R01DA034806; R21DA040777) and Natural Science Foundation of China (No. 81601163).

\section{ADDITIONAL INFORMATION}

Supplementary information accompanies this paper at https://doi.org/10.1038/ s41386-018-0017-9.

Conflict of interest: MCH is a current employee of F Hoffmann-La Roche Ltd. F Hoffmann-La Roche Ltd plays no role in the experiments and interpretation of the data. The authors declare that they have no conflict of interest.

Publisher's note: Springer Nature remains neutral with regard to jurisdictional claims in published maps and institutional affiliations.

\section{REFERENCES}

1. World Health Organization. WHO report on the global tobacco epidemic. Geneva, Switzerland: World Health Organization; 2011.

2. De Biasi M, Dani JA. Reward, addiction, withdrawal to nicotine. Annu Rev Neurosci. 2011;34:105-30

3. Subramaniyan M, Dani JA. Dopaminergic and cholinergic learning mechanisms in nicotine addiction. Ann NY Acad Sci. 2015;1349:46-63.

4. Kleijn J, Folgering $\mathrm{JH}$, van der Hart MC, Rollema $\mathrm{H}$, Cremers $\mathrm{TI}$, Westerink $\mathrm{BH}$. Direct effect of nicotine on mesolimbic dopamine release in rat nucleus accumbens shell. Neurosci Lett. 2011;493:55-58.

5. Leri F, Vaccarino FJ. Tribute to: self-administered nicotine activates the mesolimbic dopamine system through the ventral tegmental area [William Corrigall, Kathleen Coen and Laurel Adamson. Brain Res. 653 (1994) 278-284]. Brain Res. 2016;1645:61-64.

6. Stoker AK, Markou A. Unraveling the neurobiology of nicotine dependence using genetically engineered mice. Curr Opin Neurobiol. 2013;23:493-9.

7. Zhang L, Doyon WM, Clark JJ, Phillips PE, Dani JA. Controls of tonic and phasic dopamine transmission in the dorsal and ventral striatum. Mol Pharmacol. 2009;76:396-404.

8. Grandy DK, Miller GM, Li JX. "TAARgeting Addiction"-the alamo bears witness to another revolution: an overview of the Plenary Symposium of the 2015 Behavior, Biology and Chemistry Conference. Drug Alcohol Depend. 2016;159:9-16. 
9. Grandy DK. Trace amine-associated receptor 1-family archetype or iconoclast? Pharmacol Ther. 2007;116:355-90.

10. Lindemann L, Meyer CA, Jeanneau K, Bradaia A, Ozmen L, Bluethmann H, et al. Trace amine-associated receptor 1 modulates dopaminergic activity. J Pharmacol Exp Ther. 2008;324:948-56.

11. Liu JF, Siemian JN, Seaman R Jr, Zhang Y, Li JX. Role of TAAR1 within the subregions of the mesocorticolimbic dopaminergic system in cocaine-seeking behavior. J Neurosci. 2017;37:882-92.

12. Pei Y, Lee J, Leo D, Gainetdinov RR, Hoener MC, Canales JJ. Activation of the trace amine-associated receptor 1 prevents relapse to cocaine seeking. Neuropsychopharmacology. 2014;39:2299-308.

13. Thorn DA, Jing L, Qiu Y, Gancarz-Kausch AM, Galuska CM, Dietz DM, et al. Effects of the trace amine-associated receptor 1 agonist RO5263397 on abuse-related effects of cocaine in rats. Neuropsychopharmacology. 2014;39:2309-16.

14. Espinoza S, Ghisi V, Emanuele M, Leo D, Sukhanov I, Sotnikova TD, et al. Postsynaptic D2 dopamine receptor supersensitivity in the striatum of mice lacking TAAR1. Neuropharmacology. 2015;93:308-13.

15. Liu JF, Thorn DA, Zhang Y, Li JX (2016). Effects of trace amine-associated receptor 1 agonists on the expression, reconsolidation, and extinction of cocaine reward memory. Int J Neuropsychopharmacol 19.

16. Qiu Y, Zhang Y, Li JX. Discriminative stimulus effects of the imidazoline 12 receptor ligands BU224 and phenyzoline in rats. Eur J Pharmacol. 2015;749:133-41.

17. Jutkiewicz EM, Brooks EA, Kynaston AD, Rice KC, Woods JH. Patterns of nicotinic receptor antagonism: nicotine discrimination studies. J Pharmacol Exp Ther. 2011;339:194-202.

18. Mansbach RS, Chambers LK, Rovetti CC. Effects of the competitive nicotinic antagonist erysodine on behavior occasioned or maintained by nicotine: comparison with mecamylamine. Psychopharmacology (Berl). 2000;148:234-42.

19. Luo YX, Xue YX, Liu JF, Shi HS, Jian M, Han Y, et al. A novel UCS memory retrievalextinction procedure to inhibit relapse to drug seeking. Nat Commun. 2015;6:7675.

20. Wang ZJ, Martin JA, Mueller LE, Caccamise A, Werner CT, Neve RL, et al. BRG1 in the nucleus accumbens regulates cocaine-seeking behavior. Biol Psychiatry. 2016;80:652-60.

21. Liu JF, Yang C, Deng JH, Yan W, Wang HM, Luo YX, et al. Role of hippocampal beta-adrenergic and glucocorticoid receptors in the novelty-induced enhancement of fear extinction. J Neurosci. 2015;35:8308-21.

22. Thorn DA, Qiu Y, Jia S, Zhang Y, Li JX. Antinociceptive effects of imidazoline 12 receptor agonists in the formalin test in rats. Behav Pharmacol. 2016;27:377-83.

23. Chai N, Liu JF, Xue YX, Yang C, Yan W, Wang HM, et al. Delayed noradrenergic activation in the dorsal hippocampus promotes the long-term persistence of extinguished fear. Neuropsychopharmacology. 2014;39:1933-45.

24. Paxinos G, Watson C. The rat brain in stereotaxic coordinates. 7th ed. Amsterdam, Netherlands: Elsevier Academic; 2014.

25. Richardson NR, Roberts DC. Progressive ratio schedules in drug selfadministration studies in rats: a method to evaluate reinforcing efficacy. J Neurosci Methods. 1996;66:1-11.

26. Shaham Y, Adamson LK, Grocki S, Corrigall WA. Reinstatement and spontaneous recovery of nicotine seeking in rats. Psychopharmacology (Berl). 1997;130:396-403.

27. Shram MJ, Funk D, Li Z, Le AD. Nicotine self-administration, extinction responding and reinstatement in adolescent and adult male rats: evidence against a biological vulnerability to nicotine addiction during adolescence. Neuropsychopharmacology. 2008;33:739-48.

28. Shi HS, Zhu WL, Liu JF, Luo YX, Si JJ, Wang SJ, et al. PI3K/Akt signaling pathway in the basolateral amygdala mediates the rapid antidepressant-like effects of trefoil factor 3. Neuropsychopharmacology. 2012;37:2671-83.

29. Wang ZJ, Martin JA, Gancarz AM, Adank DN, Sim FJ, Dietz DM. Activin A is increased in the nucleus accumbens following a cocaine binge. Sci Rep. 2017;7:43658.

30. Harmeier A, Obermueller S, Meyer CA, Revel FG, Buchy D, Chaboz S, et al. Trace amine-associated receptor 1 activation silences GSK3beta signaling of TAAR1 and D2R heteromers. Eur Neuropsychopharmacology. 2015;25:2049-61.
31. Ferragud A, Howell AD, Moore CF, Ta TL, Hoener MC, Sabino V, et al. The trace amine-associated receptor 1 agonist RO5256390 blocks compulsive, binge-like eating in rats. Neuropsychopharmacology. 2017;42:1458-70.

32. Cahill PS, Wightman RM. Simultaneous amperometric measurement of ascorbate and catecholamine secretion from individual bovine adrenal medullary cells. Anal Chem. 1995;67:2599-605.

33. Wakabayashi KT, Bruno MJ, Bass CE, Park J. Application of fast-scan cyclic voltammetry for the in vivo characterization of optically evoked dopamine in the olfactory tubercle of the rat brain. Analyst. (Lond). 2016;141:3746-55.

34. Park J, Galligan JJ, Fink GD, Swain GM. In vitro continuous amperometry with a diamond microelectrode coupled with video microscopy for simultaneously monitoring endogenous norepinephrine and its effect on the contractile response of a rat mesenteric artery. Anal Chem. 2006;78:6756-64.

35. Hursh SR, Silberberg A. Economic demand and essential value. Psychol Rev. 2008;115:186-98.

36. Thorn DA, Zhang C, Zhang Y, Li JX. The trace amine associated receptor 1 agonist RO5263397 attenuates the induction of cocaine behavioral sensitization in rats. Neurosci Lett. 2014;566:67-71.

37. Smith JW, Stolerman IP. Recognising nicotine: the neurobiological basis of nicotine discrimination. Handb Exp Pharmacol. 2009;192:295-333.

38. Scofield MD, Kalivas PW. Astrocytic dysfunction and addiction: consequences of impaired glutamate homeostasis. Neuroscience. 2014;20:610-22.

39. Leo D, Mus L, Espinoza S, Hoener MC, Sotnikova TD, Gainetdinov RR. Taar1mediated modulation of presynaptic dopaminergic neurotransmission: role of D2 dopamine autoreceptors. Neuropharmacology. 2014;81:283-91.

40. Cotter R, Pei Y, Mus L, Harmeier A, Gainetdinov RR, Hoener MC, et al. The trace amine-associated receptor 1 modulates methamphetamine's neurochemical and behavioral effects. Front Neurosci. 2015;9:39.

41. Budygin EA, Phillips PE, Robinson DL, Kennedy AP, Gainetdinov RR, Wightman RM. Effect of acute ethanol on striatal dopamine neurotransmission in ambulatory rats. J Pharmacol Exp Ther. 2001;297:27-34.

42. Bolin BL, Reynolds AR, Stoops WW, Rush CR. Relationship between oral damphetamine self-administration and ratings of subjective effects: do subjective effects ratings correspond with a progressive-ratio measure of drug-taking behavior? Behav Pharmacol. 2013;24:533-42.

43. Schuster CR, Johanson CE. Relationship between the discriminative stimulus properties and subjective effects of drugs. Psychopharmacol Ser. 1988:4:161-75.

44. Revel FG, Moreau JL, Gainetdinov RR, Bradaia A, Sotnikova TD, Mory R, et al. TAAR1 activation modulates monoaminergic neurotransmission, preventing hyperdopaminergic and hypoglutamatergic activity. Proc Natl Acad Sci USA. 2011;108:8485-90.

45. Revel FG, Moreau JL, Pouzet B, Mory R, Bradaia A, Buchy D, et al. A new perspective for schizophrenia: TAAR1 agonists reveal antipsychotic- and antidepressant-like activity, improve cognition and control body weight. Mol Psychiatry. 2013;18:543-56

46. Manzardo AM, Stein L, Belluzzi JD. Rats prefer cocaine over nicotine in a two-lever self-administration choice test. Brain Res. 2002;924:10-19.

47. Nutt DJ, Lingford-Hughes A, Erritzoe D, Stokes PR. The dopamine theory of addiction: 40 years of highs and lows. Nat Rev Neurosci. 2015;16:305-12.

48. Robison AJ, Nestler EJ. Transcriptional and epigenetic mechanisms of addiction. Nat Rev Neurosci. 2011;12:623-37.

49. Pei Y, Asif-Malik A, Canales JJ. Trace amines and the trace amine-associated receptor 1: pharmacology, neurochemistry, and clinical implications. Front Neurosci. 2016;10:148.

50. Xie Z, Westmoreland SV, Bahn ME, Chen GL, Yang $\mathrm{H}$, Vallender EJ, et al. Rhesus monkey trace amine-associated receptor 1 signaling: enhancement by monoamine transporters and attenuation by the D2 autoreceptor in vitro. J Pharmacol Exp Ther. 2007;321:116-27.

51. Bradaia A, Trube G, Stalder $H$, Norcross RD, Ozmen L, Wettstein JG, et al. The selective antagonist EPPTB reveals TAAR1-mediated regulatory mechanisms in dopaminergic neurons of the mesolimbic system. Proc Natl Acad Sci USA. 2009;106:20081-6 